\title{
Nutritional Status among the Urban Meitei Children and Adolescents of Manipur, Northeast India
}

\author{
Maibam Samson Singh and R. K. Neeta Devi \\ Department of Anthropology, North-Eastern Hill University, Shillong, Meghalaya 793022, India \\ Correspondence should be addressed to Maibam Samson Singh; samsonsingh@ymail.com
}

Received 13 November 2012; Revised 24 December 2012; Accepted 26 December 2012

Academic Editor: Kaushik Bose

Copyright (C) 2013 M. S. Singh and R. K. N. Devi. This is an open access article distributed under the Creative Commons Attribution License, which permits unrestricted use, distribution, and reproduction in any medium, provided the original work is properly cited.

\begin{abstract}
Purpose. To determine the nutritional status (underweight and overweight) among Meitei children and adolescents. Methods. Crosssectional data on 854 subjects ( 384 boys and 470 girls) were collected during the months of May 2009 to August 2009 following house-to-house survey. An anthropometric rod and a weighing scale were used to measure height and weight. The presence of underweight and overweight has been evaluated using the international cutoff points for children and adolescents. MS-Excel software was used for all statistical analyses. Results. A high prevalence of underweight (30.21\%) and overweight (3.12\%) in the present study was found among children and adolescent boys, respectively. Among girls, the prevalence of both underweight (33.86\%) and overweight (5.18\%) was reported higher among children than adolescents, and the differences in the distribution were significant at 0.05 levels. The overall prevalence of underweight (28.29\%) was found more or less the same among boys and girls, but overweight (5.10\%) was reported higher among girls than boys (2.34\%). Conclusion. The possible reasons for both forms of malnutrition among Meitei children and adolescents could be traced through poverty, low dietary intake, socioeconomic condition, nutrition transition, and changing lifestyles. The other possible reasons could be due to peer pressure, eating habits, or emotional factor.
\end{abstract}

\section{Introduction}

Adolescence is a period of transition between childhood and adulthood that demands extra nutrients and energy-rich food for rapid growth and maturation [1]. Inadequate diet and unfavourable environmental condition in developing nations like India may adversely affect the growth and nutrition of adolescents. Malnutrition, both undernutrition and overnutrition, refers to an impairment of health, resulting from a deficiency or from an excess or imbalance of nutrients. It is of public health significance among adolescents across the world [2]. The coexistence of overweight/obesity and underweight is rather common in developing countries and is found to be increased proportionally over time [3,4]. Several studies have investigated the nutritional status of children and adolescents from different parts of India [5-7]. In India alone, there are approximately 60 million children who are underweight [8], this prevalence is higher in rural areas compared to urban areas [9]. India has one of the highest underweight burdens in the world, even twice that of subSahara region. However, India is now also beginning to experience the emerging problem of overweight $[10,11]$. A recent study among Indian children in the age group 6-18 years suggests the existence of a double burden of underweight and overweight [12]. Parallel to persistent undernutrition, obesity rates are increasing globally, including those of many low- and middle-income countries that previously had a very low prevalence $[13,14]$. Globally, an estimated 10 percent of school-aged children between 5 to 7 years of age are overweight or obese [15], and around 43 million children under age five are overweight [16]. Studies also show that the prevalence of overweight and obesity in Punjab, Maharashtra, Delhi and Chennai fluctuates between 11 and 23 percent [17]. In Northeast India, the prevalence of undernutrition (53.9\%) is found among school-aged children in Assam [18]. Another study among Khasi boys aged 3-18 years of Meghalaya shows the prevalence of underweight at 60.0 percent [19]. The prevalence of overweight among Mishing boys and girls is 
TABLE 1: Basic data on height among children and adolescents Meitei boys and girls.

\begin{tabular}{lcccccccccc}
\hline & \multicolumn{9}{c}{ Boys } & \multicolumn{3}{c}{ Girls } \\
Age (year) & $N$ & Height $(\mathrm{cm})$ & SD & $t$-value & Sig. level & $N$ & Height $(\mathrm{cm})$ & SD & $t$-value & Sig. level \\
\hline $8-12$ & 192 & 129.8 & 8.92 & \multirow{2}{*}{35.55} & $P<0.01$ & 251 & 131.9 & 10.34 & 25.77 & $P<0.01$ \\
$13-18$ & 192 & 159.6 & 7.44 & & & 219 & 151.2 & 5.46 & 2 \\
\hline
\end{tabular}

$N$ : no. of subjects and SD: standard deviation.

TABLE 2: Basic data on body weight among children and adolescents Meitei boys and girls.

\begin{tabular}{lcccccccccc}
\hline & \multicolumn{9}{c}{ Boys } & \multicolumn{4}{c}{ Girls } \\
Age (year) & $N$ & Weight $(\mathrm{kg})$ & SD & $t$-value & Sig. level & $N$ & Weight $(\mathrm{kg})$ & SD & $t$-value & Sig. level \\
\hline $8-12$ & 192 & 26.5 & 5.57 & \multirow{2}{*}{30.01} & $P<0.01$ & 251 & 27.8 & 7.19 & 24.70 & $P<0.01$ \\
$13-18$ & 192 & 47.4 & 7.97 & & & 219 & 44.4 & 7.40 & 2.40 \\
\hline
\end{tabular}

$N$ : no. of subjects and SD: standard deviation.

found to be 1.95 percent and 1.96 percent, respectively [20]. No or little research on this has yet been undertaking on other populations in the Northeast, the urban Meitei children and adolescents in Manipur state among them. The present study aims to fill this gap.

\section{Materials and Methods}

Manipur is a hilly region. Only about 10 percent of the area is plain and is surrounded by rolling hills. In the Imphal Valley, the Meitei constitute the bulk of Manipur's population besides the Muslims (Meitei Pangals) and Schedule Castes people residing in the valley. In addition to this, a small percentage of other groups have migrated from time to time from the hills and other parts of mainland India. In the past few years, Manipur has undergone tremendous changes, rapid urbanization and socioeconomic development among them. Such a transition has, over the years, resulted in changes among Meitei population in terms of occupation, economy, food consumption, dietary intake, physical activity levels, and overall lifestyles. A nutritional transition characterised by growing consumption of energy-rich diet, processed and fast food from restaurants, and roadside vendors is observed among Meitei children and adolescents.

The present study was conducted among Meitei children and adolescents residing in the urban areas of Lamphel subdivision under Imphal West District of Manipur. Crosssectional data on 384 Meitei boys and 470 Meitei girls aged 8-18 years were collected for the present study. Since the range of age distribution was wide, the study subjects were divided in two age groups: 8-12 years age group, considered to be children, and 13-18 years age group, considered to be adolescents $[21,22]$. The data on each subject were collected by the random sampling method, using houseto-house visit during the months of May 2009 to August 2009. Measurements were taken on those subjects who were willing and cooperative. Most of the subjects for the present study belonged to lower income family groups (47.18\%), followed by middle-income family groups $(27.98 \%)$, and high-income family groups (24.82\%). An anthropometric rod and a weighing scale to the nearest of $0.1 \mathrm{~cm}$ and $0.5 \mathrm{~kg}$, respectively, was used to measure height and weight following the standard technique of Lohman et al. [23]. The parameters taken were analyzed statistically to find out the mean and the standard deviation. In order to test the level of significance, both $t$-test and chi-square test have been used. The values of $P<0.05$ and $P<0.01$ were used to find different significant levels of calculated $t$-test and chi-square value. The presence of underweight and overweight has been evaluated using the international cutoff points for children, and adolescents [24]. MS-Excel software was used for all statistical analyses of the present research.

\section{Results}

The mean, standard deviation, and $t$-value with the level of significance of both height and body weight among boys and girls are given in Tables 1 and 2. The tables show that both height and body weight increased along with the increase in age. The mean height $(159.6 \mathrm{~cm})$ was found higher among adolescent boys than among children $(129.8 \mathrm{~cm})$. The difference in the mean height was found to be statistically significant $(P<0.01)$. Similarly, the mean height $(151.2 \mathrm{~cm})$ was also reported higher among adolescent girls as compared to that of children $(131.9 \mathrm{~cm})$, and the difference was significant statistically $(P<0.01)$. The mean body weight was observed to be heavier among adolescent boys $(47.4 \mathrm{~kg})$ and adolescent girls $(44.4 \mathrm{~kg})$ when compared to that of the children (Table 2 ). The results further show that the mean height and weight among children (8-12 years) was reported higher among girls than boys, whereas among adolescents (13-18 years), it was found higher among boys.

Table 3 shows the distribution of mean BMI values among boys and girls. The mean BMI values show increases along with the increase in age in both sexes. The mean BMI (18.54) was found higher among adolescent boys than children (15.54). Similarly, mean BMI (19.34) was also recorded higher among adolescent girls than children (15.75\%). The increase in mean BMI value between children and adolescents was found to be statistically significant $(P<0.01)$ in both sexes.

The prevalence of underweight and overweight among boys and girls is given in the Table 4 . This table shows that the prevalence of underweight was very high when 
TABLE 3: Distribution of mean BMI value among children and adolescents Meitei boys and girls.

\begin{tabular}{|c|c|c|c|c|c|c|c|c|c|c|}
\hline \multicolumn{6}{|c|}{ Boys } & \multicolumn{5}{|c|}{ Girls } \\
\hline Age (year) & $N$ & BMI & $\mathrm{SD}$ & $t$-value & Sig. level & $N$ & BMI & SD & $t$-value & Sig. level \\
\hline $8-12$ & 192 & 15.54 & 1.79 & 1409 & $P<$ & 251 & 15.75 & 2.27 & 1584 & \\
\hline $13-18$ & 192 & 18.54 & 2.33 & 14.09 & $<0.01$ & 219 & 19.34 & 2.60 & .84 & 1 \\
\hline
\end{tabular}

$N$ : no. of subjects and SD: standard deviation.

TABLE 4: Prevalence of overweight and obesity among children and adolescent Meitei boys and girls (IOTF).

\begin{tabular}{|c|c|c|c|c|c|c|}
\hline Age & $N$ & Underweight & Normal & Overweight & Chi-value & Sig. level \\
\hline \multicolumn{7}{|c|}{ Boys } \\
\hline $8-12$ & 192 & $58(30.21 \%)$ & $131(68.23 \%)$ & $3(1.56 \%)$ & \multirow{2}{*}{1.686} & \multirow{2}{*}{$P>0.05$} \\
\hline $13-18$ & 192 & $50(26.04 \%)$ & $136(70.83 \%)$ & $6(3.12 \%)$ & & \\
\hline Total & 384 & $108(28.12 \%)$ & $267(69.53 \%)$ & $9(2.34 \%)$ & & \\
\hline \multicolumn{7}{|c|}{ Girls } \\
\hline $8-12$ & 251 & $85(33.86 \%)$ & $153(60.96 \%)$ & $13(5.18 \%)$ & \multirow{2}{*}{8.477} & \multirow{2}{*}{$P<0.05$} \\
\hline $13-18$ & 219 & $48(21.92 \%)$ & $160(73.06 \%)$ & $11(5.02 \%)$ & & \\
\hline Total & 470 & $133(28.29 \%)$ & $313(66.59 \%)$ & $24(5.10 \%)$ & & \\
\hline
\end{tabular}

IOTF: International Obesity Task Force.

compared to overweight in all of the different age groups in both boys and girls. A high prevalence of underweight (30.21\%) and overweight $(3.12 \%)$ was found among children and adolescent boys, respectively. The differences were not significant statistically. In the case of girls, the prevalence of both underweight (33.86\%) and overweight (5.18\%) was found to be higher among children than adolescents. The differences in the prevalence of underweight and overweight were significant $\left(\chi^{2}=8.477, P<0.05\right)$. The table further indicated that the overall prevalence of underweight (28.29\%) was found more or less the same among boys and girls, but overweight $(5.10 \%)$ was reported higher among girls than boys $(2.34 \%)$.

\section{Discussion}

The present study shows that height and body weight increases along with the advancing of age in both Meitei boys and girls. Overall socioeconomic development in the last few decades and improvements in nutrition are likely among the factors that explain the increase in both height and body weight observed in the present research. The age groups wise comparison also shows that girls are slightly taller and heavier than boys in the age group 8-12 years, whereas boys are taller and heavier than girls in the age group 13-18 years. The probable reasons for this include the early occurrence of adolescent growth spurt among girls.

An increasing trend of overweight and obesity in combination with a high prevalence of underweight is found to be common in many developing countries [3]. The present study shows high occurrence of underweight, which is more or less the same in both sexes. However, the prevalence of overweight is found higher among girls than boys. The frequency of overweight is low compared to that of underweight. One possible reason for the high occurrence of underweight could be traced to poverty, low dietary intake, excessive energy outflows due to hard labour, and chronic infections [25]. The other possible reasons could be explained through factors such as biological, emotional, physical appearance, and behavioural factors. This, however, needs to be asserted by further research. In any case, several studies show that peer pressure, eating habits or emotional factors, and need to maintain an acceptable physical appearance are important factors that may result in underweight $[13,26]$. The nutritional problems due to nutrition transition could be another reasons for both forms of malnutrition occurring in Manipur similar to those experienced in many developing countries [13].

The new millennium has signalled an important transition for our species with more people being overweight than underweight globally $[10,27]$. In several of the developing nations across the world and even Africa, a continent usually associated with starvation, the prevalence of overweight/obesity is increasing $[27,28]$. The basic reasons accounting for this change over the last three decades are attributed to a nutrition transition [29]. This transition involves a shift in diets of populations towards increasing consumption of energy dense foods and high calorie liquids, as well as an increasing and more stable access to low-priced processed foods [30, 31]. Improvements in socioeconomic status of populations are often attributed as another reason $[32,33]$. Increasing levels of urbanization, mechanization of jobs, transportation, and dependence on television for leisure along with parallel declines in physical activity have increased sedentary behaviours of both children and adults [29, 3439]. These rapidly changing diets and lifestyles are fuelling the global obesity epidemic [39]. The globalization of fast food is also beginning to affect children's eating patterns in many countries undergoing nutrition transition [40].

Likewise, Imphal has beginning to experience tremendous changes along above lines. Urbanization has accelerated, and so has socioeconomic status of many of its inhabitants 
improved significantly. This, in turn, has resulted in significant changes in the overall lifestyle of the Meitei population. The impact of nutrition transition can be seen through the changing food environment in Manipur [41]. Such a transition has come together with changes in food habits, especially in terms of increasing consumption of processed foods, fast foods, and meals prepared by roadside vendors. This is likely among the reasons explaining the prevalence of overweight among Meitei children and adolescents, which is concluded by the present research.

The patterns of overweight/obesity differ by age, sex, rural or urban residence, and socioeconomic position and vary between and within countries [42]. The higher prevalence of overweight among girls in the present study is consistent with the gender differences in other Indian studies and other parts of the world [43-48]. This higher prevalence of overweight among girls may be related to the adolescent growth spurt and the effects of hormonal surge that occurs earlier in girls [49].

In conclusion, our study highlights the double burdens of underweight and overweight, though underweight is a more urgent problem than overweight among Meitei children and adolescents. Therefore, to reduce both forms of malnutrition, with special attention to underweight, it is essential to educate and create awareness programmes at the community levels. Government and nongovernmental organizations should be involved in creating and protecting an environment that supports the healthy growth and development of children and adolescents. Health education programs and effective policies are urgently required to promote healthy eating and physical activity and to ensure adequate access to health services. Further studies need to be conducted in order to understand clearly whether the coexistence of underweight and overweight among Meitei children and adolescents is related to the influence of socioeconomic conditions, nutritional status, due to cultural and lifestyles, or any other yet unanticipated reasons.

\section{Acknowledgments}

The authors are grateful to all the subjects and parents under study for their cooperation and patience during the time of fieldwork. They are also thankful to their supervisor Dr. J. W. Dkhar for his support and help rendered.

\section{References}

[1] K. Anand, S. Kant, and S. K. Kapoor, "Nutritional status adolescents school children in rural North India," Indian Pediatrics, vol. 36, no. 8, pp. 810-815, 1999.

[2] A. Mukhopadhyay, M. Bhadra, and K. Bose, "Anthropometric assessment of nutritional status of adolescents of Kolkata, West Bengal," Journal of Human Ecology, vol. 18, no. 3, pp. 213-216, 2005.

[3] C. M. Doak, L. S. Adair, C. Monteiro, and B. M. Popkin, "Overweight and underweight coexist within households in Brazil, China and Russia," Journal of Nutrition, vol. 130, no. 12, pp. 2965-2971, 2000.
[4] B. Caballero, "The global epidemic of obesity: an overview," Epidemiologic Reviews, vol. 29, no. 1, pp. 1-5, 2007.

[5] A. N. Kanade, S. B. Joshi, and S. Rao, "Undernutrition and adolescent growth among rural Indian boys," Indian Pediatrics, vol. 36, no. 2, pp. 145-156, 1999.

[6] N. Singh and C. P. Mishra, "Nutritional status of adolescent girls of a slum community of Varanasi," Indian journal of public health, vol. 45, no. 4, pp. 128-134, 2001.

[7] K. Venkaiah, K. Damayanti, M. U. Nayak, and K. Vijayaraghavan, "Diet and nutritional status of rural adolescents in India," European Journal of Clinical Nutrition, vol. 56, no. 11, pp. 1119-1125, 2002.

[8] "Nutrition for improved development out-comes," 5th Report on the World Nutrition Situation, United Nations Administrative Committee on Coordination/Standing Committee on Nutrition, Geneva, Switzerland, 2004.

[9] L. C. Smith, M. T. Ruel, and A. Ndiaye, "Why is child malnutrition lower in urban than in rural areas? Evidence from 36 developing countries," World Development, vol. 33, no. 8, pp. 1285-1305, 2005.

[10] M. A. Mendez, C. A. Monteiro, and B. M. Popkin, "Overweight exceeds underweight among women in most developing countries," American Journal of Clinical Nutrition, vol. 81, no. 3, pp. 714-721, 2005.

[11] M. Gragnolati, M. Shekar, M. D. Gupta, C. Bredenkamp, and Y. K. Lee, India's Undernourished Children: A Call for Reform and Action, The International Bank for Reconstruction and Development/The World Bank, Washington, DC, USA, 2005.

[12] G. Srihari, A. Eilander, S. Muthayya, A. V. Kurpad, and S. Seshadri, "Nutritional status of affluent indian school children: what and how much do we know?" Indian Pediatrics, vol. 44, no. 3, pp. 204-213, 2007.

[13] P. Hossain, B. Kawar, and M. El Nahas, "Obesity and diabetes in the developing world-a growing challenge," National England Journal of Medicine, vol. 356, pp. 213-215, 2007.

[14] S. Subramanian, J. M. Perkins, E. Özaltin, and G. D. Smith, "Weight of nations: a socioeconomic analysis of women in low- to middle-income countries," American Journal of Clinical Nutrition, vol. 93, no. 2, pp. 413-421, 2011.

[15] D. R. Bharati, P. R. Deshmukh, and B. S. Garg, "Correlates of overweight \& obesity among school going children of Wardha city, central India," Indian Journal of Medical Research, vol. 127, no. 6, pp. 539-543, 2008.

[16] World Health Organization Childhood Obesity Fact Sheet 311, updated on March 2011, http://www.who.int/mediacentre/ factsheets/fs311/en/index.html.

[17] S. Kaur, U. Kapil, and P. Singh, "Pattern of chronic diseases amongst adolescent obese children in developing countries," Current Science, vol. 88, no. 7, pp. 1052-1056, 2005.

[18] G. K. Medhi, A. Barua, and J. Mahanta, "Growth and nutritional status of school age children (6-14 years) of tea garden worker of Assam," Journal of Human Ecology, vol. 19, pp. 83-85, 2006.

[19] R. Khongsdier and N. Mukherjee, "Growth and nutritional status of Khasi boys in Northeast India relating to exogamous marriages and socioeconomic classes," American Journal of Physical Anthropology, vol. 122, no. 2, pp. 162-170, 2003.

[20] M. Sikdar, "Prevalence of malnutrition among the mising children of Northeast India: a comparison between four different sets of criteria," North American Journal of Medical Science, vol. 4, no. 7, pp. 305-309, 2012. 
[21] S. Tharkar and V. Viswanathan, "Impact of socioeconomic status on prevalence of overweight and obesity among children and adolescents in urban India," The Open Obesity Journal, vol. 1, pp. 9-14, 2009.

[22] D. J. Kumari and B. S. H. Krishna, "Prevalence and risk factors for adolescents (13-17 years) overweight and obesity," Current Science, vol. 100, no. 3, pp. 373-377, 2011.

[23] T. G. Lohman, A. F. Roch, and R. Martorell, Anthropometric Standardization Reference Manual, Human Kinetics Books, Chicago, Ill, USA, 1998.

[24] T. J. Cole, M. C. Bellizzi, K. M. Flegal, and W. H. Dietz, "Establishing a standard definition for child overweight and obesity worldwide: international survey," British Medical Journal, vol. 320, no. 7244, pp. 1240-1243, 2000.

[25] M. Ramzan, I. Ali, and A. S. Khan, "Body mass status of school children of Dera Ismail Khan, Pakistan," Journal of Ayub Medical College, Abbottabad, vol. 20, no. 4, pp. 119-121, 2008.

[26] B. Werner, A. Magnuson, and L. Bodin, "Increasing rate of weight loss among schoolchildren, especially girls, in Sweden," Journal of Adolescent Health, vol. 40, no. 3, pp. 238-244, 2007.

[27] A. A. Brewis, Obesity: Cultural and Bio Cultural Perspectives, Rutgers University Press, New Brunswick, NJ, USA, 2012.

[28] M. Berman, "Africa-yes, Africa-has an obesity problem," Newsweek, 2009, http://www.newsweek.com/id/212556.

[29] B. M. Popkin, "The nutrition transition: an overview of world pattern of change," Nutrition Review, vol. 62, pp. 140S-143S, 2004.

[30] A. Drewnowski and B. M. Popkin, "The nutrition transition: new trends in the global diet," Nutrition Reviews, vol. 55, no. 2, pp. 31-43, 1997.

[31] B. M. Popkin, The World Is Fat: the Fads, Trends, Policies, and Products That Are Fattening the Human Race, Avery, New York, NY, USA, 2009.

[32] J. Sobal and A. J. Stunkard, "Socioeconomic status and obesity: a review of the literature," Psychological Bulletin, vol. 105, no. 2, pp. 260-275, 1989.

[33] K. Bose, M. Bhadraand, and A. Mukhopadhyay, "Causes and consequences of obesity," in Anthropology Today: Trends, Scope and Applications, V. Bhasin and M. K. Bhasin, Eds., pp. 223-240, Kamla Raj Enterprise, Delhi, India, 2007.

[34] J. O. Hill and J. C. Peters, "Environmental contributions to the obesity epidemic," Science, vol. 280, pp. 1371-1374, 1998.

[35] R. E. Jeffrey and S. A. French, "Epidemic obesity in the United States: are fast foods and television viewing contributing?" American Journal of Public Health, vol. 88, pp. 277-280, 1998.

[36] A. C. Bell, K. Ge, and B. M. Popkin, "The road to obesity or the path to prevention: motorized transportation and obesity in China," Obesity Research, vol. 10, no. 4, pp. 277-283, 2002.

[37] K. D. Brownell, "The environment and obesity," in Eating Disorders and Obesity: A Comprehensive Handbook, C. G. Fairburn and K. D. Brownell, Eds., pp. 433-438, Guilford Press, New York, NY, USA, 2nd edition, 2002.

[38] J. Erlichman, A. L. Kerbey, and W. P. T. James, "Physical activity and its impact on health outcomes. Paper 2: prevention of unhealthy weight gain and obesity by physical activity: an analysis of the evidence," Obesity Reviews, vol. 3, no. 4, pp. 273-287, 2002.

[39] WHO, "Diet, nutrition and the prevention of chronic diseases. Report of a Joint WHO/FAO Expert Consultation," Tech. Rep. no. 916, World Health Organization, Geneva, Switzerland, 2003.
[40] S. J. Ulijaszek and H. Lofink, "Obesity in biocultural perspective," Annual Review of Anthropology, vol. 35, pp. 337-360, 2006.

[41] J. W. Dkhar and M. S. Singh, "Prevalence of overweight and obesity among the Meitei adolescent of Manipur, India," Anthropologist, vol. 14, no. 4, pp. 347-351, 2012.

[42] A. Matijasevich, C. G. Victora, J. Golding et al., "Socioeconomic position and overweight among adolescents: data from birth cohort studies in Brazil and the UK," BMC Public Health, vol. 9, article no. 105, 2009.

[43] U. Kapil, P. Singh, P. Pathak, S. N. Dwivedi, and S. Bhasin, "Prevalence of obesity amongst affluent adolescent school children in Delhi," Indian Pediatrics, vol. 39, no. 5, pp. 449-452, 2002.

[44] N. Stettler, P. Bovet, H. Shamlaye, B. S. Zemel, V. A. Stallings, and F. Paccaud, "Prevalence and risk factors for overweight and obesity in children from Seychelles, a country in rapid transition: the importance of early growth," International Journal of Obesity, vol. 26, no. 2, pp. 214-219, 2002.

[45] R. Kruger, H. S. Kruger, and U. E. MacIntyre, "The determinants of overweight and obesity among 10- to 15-year-old schoolchildren in the North West Province, South Africa-The THUSA BANA (Transition and Health during Urbanisation of South Africans; BANA, children) study," Public Health Nutrition, vol. 9, no. 3, pp. 351-358, 2006.

[46] R. K. Marwaha, N. Tandon, Y. Singh, R. Aggarwal, K. Grewal, and K. Mani, "A study of growth parameters and prevalence of overweight and obesity in school children from Delhi," Indian Pediatrics, vol. 43, no. 11, pp. 943-952, 2006.

[47] S. Sidhu, N. Kaur, and R. Kaur, "Overweight and obesity in affluent school children of Punjab," Annals of Human Biology, vol. 33, no. 2, pp. 255-259, 2006.

[48] U. P. Ben-Bassey, A. O. Oduwole, and O. O. Ogundipe, "Prevalence of overweight and obesity in Eti-Osa LGA, Lagos, Nigeria," Obesity Reviews, vol. 8, no. 6, pp. 475-479, 2007.

[49] J. Chhatwal, M. Verma, and S. K. Riar, "Obesity among preadolescent and adolescents of a developing country (India)," Asia Pacific Journal of Clinical Nutrition, vol. 13, no. 3, pp. 231-235, 2004. 

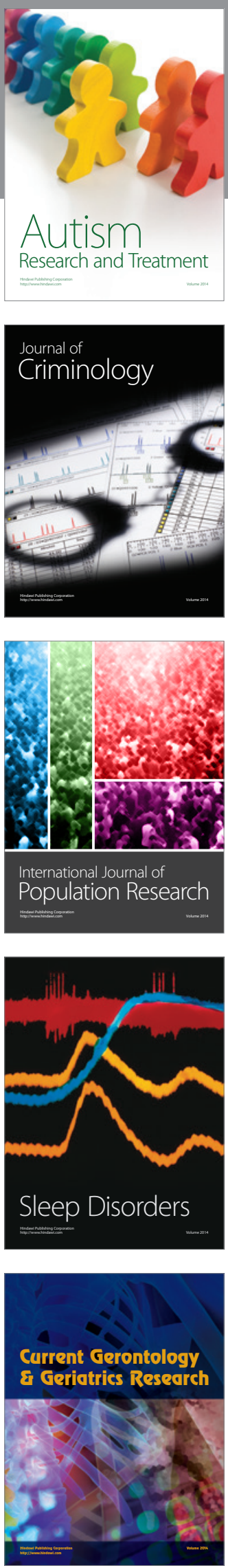
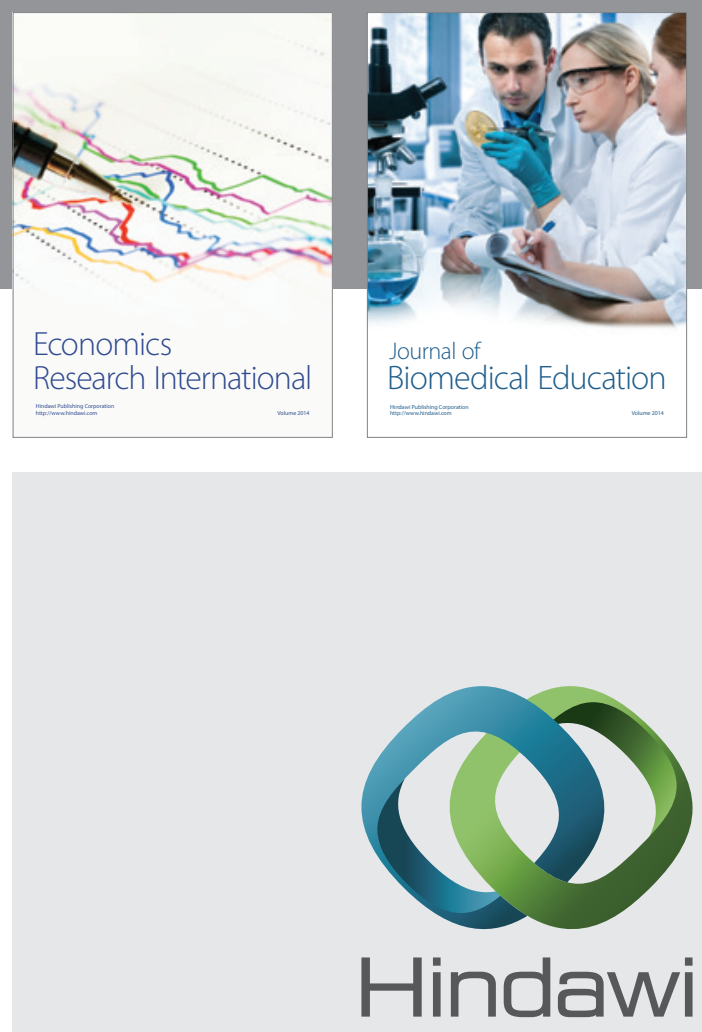

Submit your manuscripts at

http://www.hindawi.com
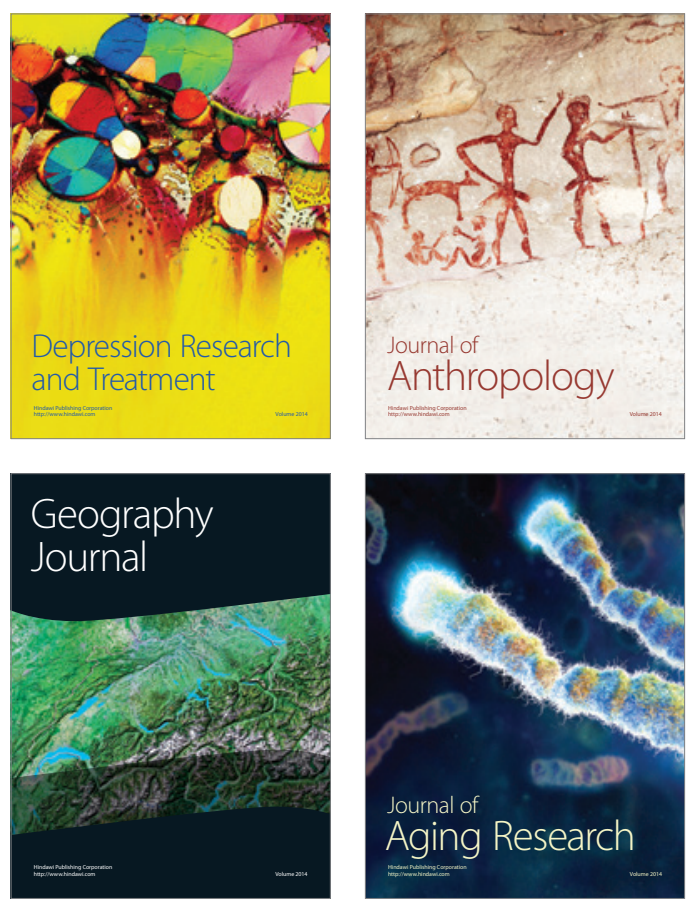
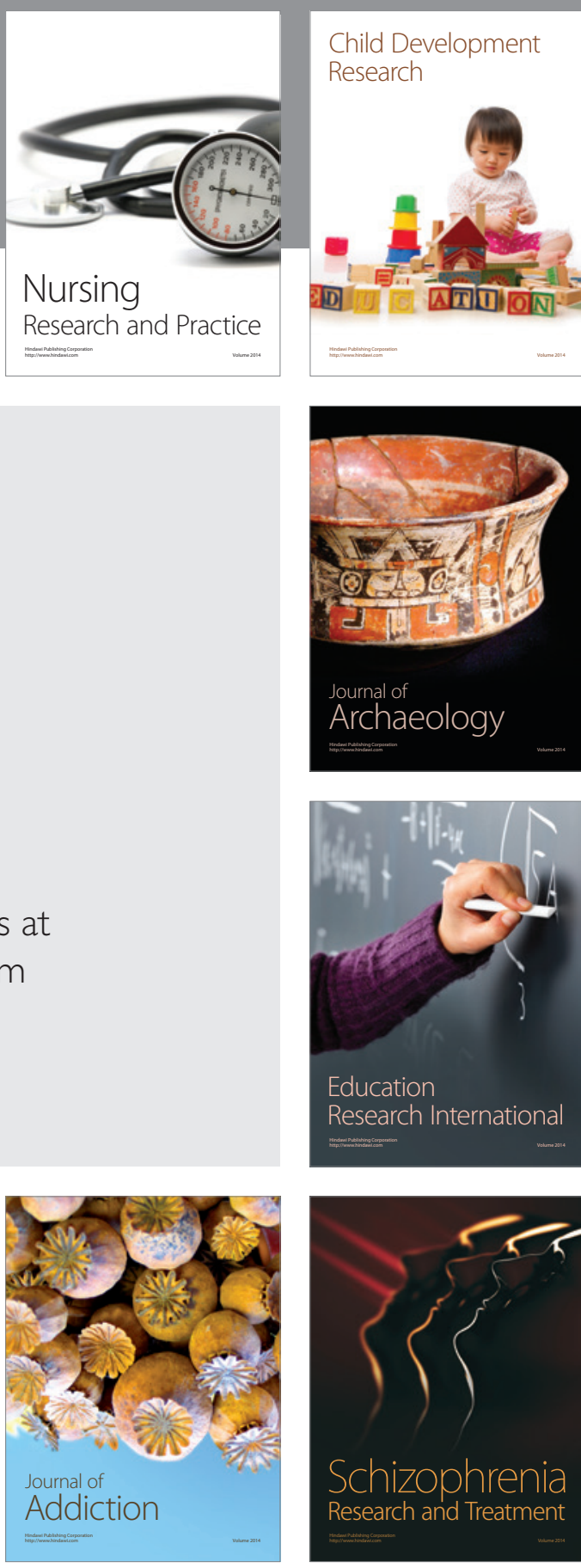

(D)
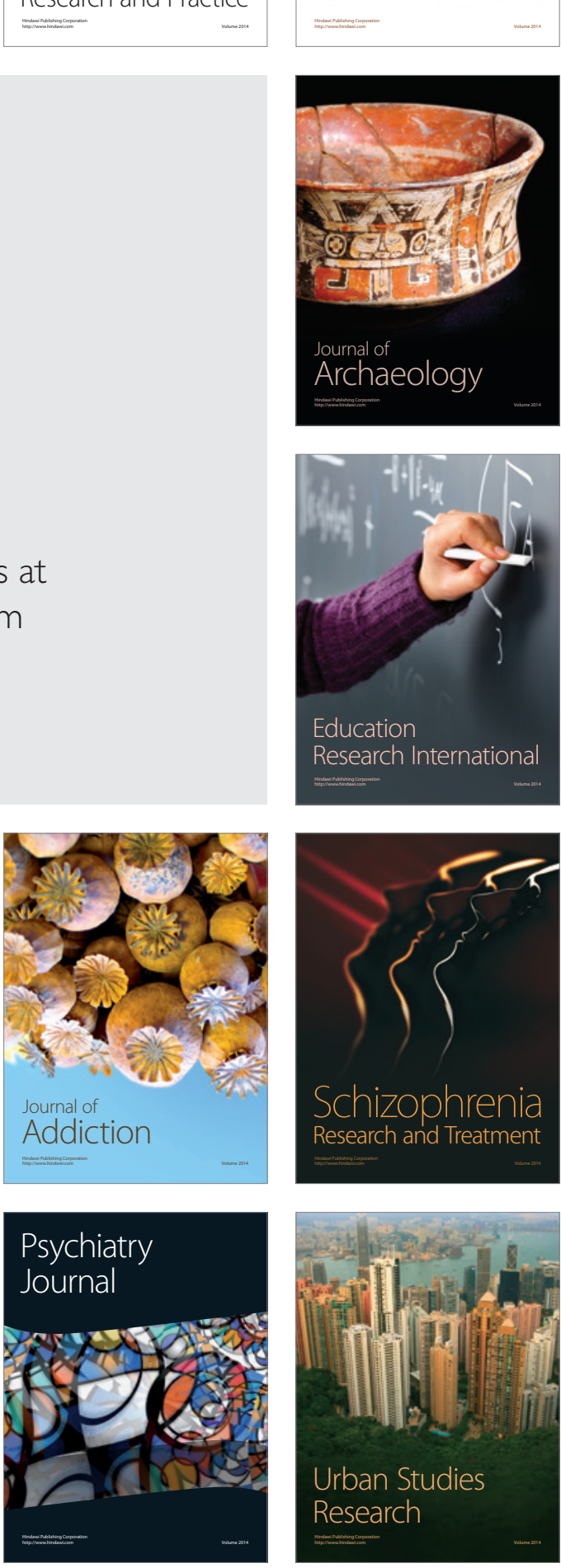